\title{
Development and Characterization of Thermosensitive intranasal Gel Containing Paliperidone Loaded Microspheres
}

\author{
Apurva Jatinbhai Maniyar, Grishma Mahendrabhai Patel, Pragna Krishnachandra Shelat, Anita Nanikram Lalwani* \\ Department of Pharmaceutics, K. B. Institute of Pharmaceutical Education And Research, Gandhinagar, Gujarat, INDIA..
}

\begin{abstract}
Purpose: The objective of the present investigation was to fabricate a thermosensitive gel containing paliperidone loaded microspheres for the treatment of schizophrenia for brain delivery through nasal route. Incorporation of drug in to microspheres and then in to gel should increase the duration of release and nasal duration time respectively. Material and Method: Ethyl cellulose microspheres containing paliperidone palmitate were prepared by emulsification of ethyl acetate dispersion containing polymer and drug with aqueous external phase containing polysorbate 80. Amount of ethyl cellulose and polysorbate 80 were identified as critical formulation variables influencing the drug release at critical time points, percentage yield and particle size. These factors were studied using 2 factors and 3 level face centered factorial design using Design Expert ${ }^{\circledR}$. Drug-excipient compatibility was ascertained using FTIR analysis. The paliperidone microspheres were then incorporated in to Pluronic F127 and HPMC gel having required thermo sensitive and muco adhesive properties. Gel containing microspheres was subjected to Ex vivo permeation study, irritation study using sheep nasal mucosa and pharmacodynamic study (spontaneous motor activity in mice). Results: Microspheres that could sustain the drug release
\end{abstract}

up to 8 hours were developed. Thermoreversible gel having required thermo sensitive and muco adhesive properties was developed. The Ex vivo permeation study and pharm a codynamic study of the drug loaded microsphere containing gel confirmed the release up to 8 hours. The histopathology study showed absence of irritation on sheep nasal mucosa. Conclusion: Paliperidone palmitate loaded microspheres containing gel could prolong and target the drug release to brain and therefore give prolonged and intense action.

Key words: Nose to brain delivery, Paliperidone palmitate, Pharmacodynamic activity, Thermoreversible gel, Desirability index.

Correspondence :

Lalwani Anita Nanikram,

Department of Pharmaceutics, K. B. Institute of Pharmaceutical Education and Research, Gandhinagar, Gujarat, INDIA.

Phone no: +9198983 20018

E-mail: anitanlalwani@yahoo.co.in

DOI: 10.5530/jyp.2016.4.12

\section{INTRODUCTION}

Schizophrenia is a recurrent and chronic disease, so long-term treatment with antipsychotic medications is usually required. Paliperidone palmitate (PP) has been shown to be an effective and tolerated second generation antipsychotic agent, especially in the treatment of schizophrenia. ${ }^{1}$ Paliperidone works by inhibiting serotonergic type 2 receptors (5-HT2A) and dopamine type 2 receptors (D2). ${ }^{2-4}$ Paliparidone belongs to BCS class II and has limited oral bioavailability.

Nasal route is particularly fascinating for the drugs that act on central nervous system (CNS). Direct transfer in to brain through olfactory region circumventing the $\mathrm{BBB}$ allows CNS acting drugs to promptly and effectively control problems like epilepsy, schizophrenia, dementia and several such ailments. A whole gamut of research has proved that such conditions can be better handled if nose to brain delivery is opted. ${ }^{5}$ The nasal mucosa is highly vascularized and therefore faster onset of action and enhanced bioavailability are expected. ${ }^{6}$ Selective delivery in to the brain and therefore prompt action comparable to intravenous administration, non invasive nature and minimum systemic exposure make this route most preferred. ${ }^{7}$ Additionally the nasal route circumvents the problems associated with oral route i.e. presystemic drug metabolism. ${ }^{8}$

However restrictions due to the capacity of nasal cavity and the mucocilliary clearance put limit on the volume and nature of the formulation. Excess formulation drains out into the pharynx and is swallowed. Additionally the physicochemical characteristics of the drug decide its diffusion through the nasal membrane. ${ }^{9}$ Drugs that have lower molecular weight and are lipophilic stand a better chance of getting absorbed by nasal route. Drug that have high dose would be difficult to accommodate in nasal cavity. Hydrophilic molecules are very soluble in mucus (which is mainly constituted of water) and are thus most sensitive to mucociliary clearance..$^{10}$ Increasing mucoadhesion of the liquid formulation or incorporating the drug containing carrier in to mucoadhesive gel have been the strategies to combat mucocilliary clearance and increase the residence time in nasal cavity. The aqueous solution of poloxamer has thermoreversible properties i.e. it is in sol form at lower temperatures and becomes hydrogel at a higher temperature. Poloxamer 407, available under the trade name of Pluronic F127 from BASF, has been proved to be innocuous and been used for rectal, ocular and oral administration with good tolerability. Intranasal administration of mucoadhesive MEs of sumatriptan, ${ }^{11,12}$ clonazepam ${ }^{13}$ and tacrine ${ }^{14}$ revealed higher brain/blood ratios compared to intravenous (i.v.) suggesting effective brain targeting.

In the present investigation the experiments were divided in three different stages. Microspheres containing drug and having suitable release characteristics were developed as a first step. Next thermo reversible gel having suitable gelation and mucoadhesive properties was developed. Microspheres containing drug were dispersed in the developed formulation of gel and thoroughly characterized for its permeation function, pharmacodynamic capabilities, nasal irritation potential and finally stability.

\section{MATERIAL AND METHODS}

\section{Materials}

Paliperidone palmitate (PP) was obtained as gift sample from Sun Pharma, India. Ethyl cellulose and ethyl acetate were procured from Suvidhinath Lab, India; Tween 80 was purchased from Atlas Chemical Industries. Pluronic F127 was obtained as generous gift from BASF, Mumbai, India; HPMC was purchased from Yarrow Chemical Products. 


\section{Preparation of microspheres ${ }^{15}$}

PP microspheres were prepared based on o/w emulsion solvent evaporation technique by using ethyl cellulose as a polymer. Ethyl cellulose and drug were dispersed in ethyl acetate $(40 \mathrm{ml})$ to form the oil phase. This solution was poured slowly in the $500 \mathrm{ml}$ of distilled water (aqueous phase) containing Tween 80 as the emulsifying agent with continuous stirring on propeller stirrer (Remi, india). The resultant mixture was emulsified at speed $1000 \mathrm{rpm}$ for $4 \mathrm{~h}$. The dispersed drug and polymer solution transformed into fine droplets, which subsequently solidified into rigid microspheres due to the solvent evaporation. The particles were collected by filtration, washed to remove excess oil by distilled water and dried in hot air oven at $60^{\circ} \mathrm{C}$ and stored at ambient conditions till further use (Table 1).

\section{Evaluation of microspheres Percentage yield}

The dried microspheres were weighed and percentage yield of the prepared microspheres was calculated by using the equation 1 .

$$
\text { Percentage yield }=\left\{\frac{\text { (weight of microspheres }}{\text { weight of polymer }+ \text { drug }}\right\} \times 100
$$

\section{Particle size analysis ${ }^{16}$}

Particle size of the microspheres was determined by optical microscopy. The eye piece micrometer was calibrated with the help of a stage micrometer. The particle diameters of more than 100 microspheres were measured randomly. The average particle size was then determined.

\section{Drug entrapment efficiency ${ }^{16}$}

Microspheres were crushed using a glass mortar by pestle and equivalent to $5 \mathrm{mg}$ of drug weighed. These microspheres were suspended in $25 \mathrm{ml}$ of phosphate buffer $\mathrm{pH} 6.8$. After $24 \mathrm{~h}$, the solution was filtered; $1 \mathrm{ml}$ of the filtrate was pipetted out and diluted to $10 \mathrm{ml}$ and analyzed for the drug content using UV visible1spectrophotometer at $271 \mathrm{~nm}$. The drug entrapment efficiency was calculated using the equation 2 :

$$
\text { Drug entrapment efficiency }=\left(\frac{\text { practical drug content }}{\text { theoretical drug content }}\right) \times 100
$$

\section{In vitro release study ${ }^{17}$}

Drug dissolution test of microspheres was performed by USP II paddle type apparatus. Microspheres equivalent to $20 \mathrm{mg}$ of drug were added to $400 \mathrm{ml}$ dissolution media. The content was rotated at $100 \mathrm{rpm}$ at $37^{\circ} \mathrm{C} \pm 0.5^{\circ} \mathrm{C}$. The $\mathrm{pH}$ of dissolution media was kept 6.8 for $8 \mathrm{hrs} .5 \mathrm{ml}$ of each sample were withdrawn from the dissolution medium at various time intervals and replaced by an equal volume of dissolution medium. After filtration and suitable dilution, the samples were analysed spectrophotometrically at $271 \mathrm{~nm}$. The concentration of paliperidone palmitate in sample was calculated based on calibration curves of drug. The cumulative percent release data documented were the average of 6 tablets.

\section{Factorial Design}

Polymer amount (ethyl cellulose) and surfactant amount (Tween 80) were studied at three different levels in a face centered factorial design. Percentage drug release at three different time points viz. $30 \mathrm{~min}, 240 \mathrm{~min}$ and $480 \mathrm{~min}$, percentage yield and particle size were taken as responses. The design matrix of the experiments is given in Table 1. Mathematical models [equation 3] are generated equating the factors to the responses.

$$
\mathrm{Y}=\beta_{0}+\beta_{1} \mathrm{X}_{1}+\boldsymbol{\beta}_{2} \mathrm{X}_{2}+\boldsymbol{\beta}_{11} \mathrm{X}_{1}^{2}+\boldsymbol{\beta}_{22} \mathrm{X}_{2}^{2}+\beta_{12} \mathrm{X}_{1} \mathrm{X}_{2}
$$

Where $\beta_{0}$, the intercept is the arithmetic mean of all quantities outcomes from nine runs, $\beta i$ are the coefficients computed from the observed experimental values of $Y$, and $X_{1}$ and $X_{2}$ are the coded levels of the independent variables and $X_{1} X_{2}$ and $X i 2(i=1,2)$ are the interaction and polynomial terms, respectively.

\section{Characterization of microspheres of the best batch Compatibility studies using FTIR}

The compatibility studies were carried out at room temperature by Fourier transform infrared (FTIR) spectroscopy to determine the interaction of drug with other excipients used in the formulation. The IR spectra of drug alone and physical mixtures of the drug with proposed excipient (ethyl cellulose) in the ratio of 1:1 were prepared. 1 part of this mixture was triturated with 100 parts of KBR and compressed to form pellet which was then analysed by FTIR (FTIR, 8400S, Shimadzu, Germany).

\section{Differential Scanning Calorimetry}

The thermo analytical examinations were carried out with a differential scanning calorimeter equipped with a thermal analysis data system (DSC Q20 V24.9 Build 121). Samples weighing 3-5 mg were heated in flat-bottomed sealed aluminum pans over a temperature range of $25-300^{\circ} \mathrm{C}$ at a constant rate of $10^{\circ} \mathrm{C} / \mathrm{min}$ under nitrogen purge of $50 \mathrm{ml} / \mathrm{min}$ using empty aluminum pan as reference.

\section{Scanning Electron Microscopy (SEM)}

The shape and surface morphology of the prepared microspheres were observed by scanning electron microscope (SEM) (model JSM T200, Jeol Ltd., Japan).

\section{Kinetics of drug release}

In order to understand the mechanism of drug release, percentage drug release data was treated using kinetic models such as zero order, first order, Higuchi model and Peppas model. Criteria for selecting the most appropriate model were based on best goodness of fit.

\section{Preparation of thermo reversible gel}

PF-127 (20\%) and HPMC K14 (0.5, 1, 2\%) were solubilized in cold distilled water. To this $4 \%$ mannitol was added as an isotonic agent and $0.05 \%$ benzalkonium chloride which acts as a preservative. These solutions were prepared in aseptic conditions, by dissolution in sterile water at $2^{\circ} \mathrm{C}$. The liquid was left at $4^{\circ} \mathrm{C}$ overnight until a clear solution was obtained.

\section{Evaluation of the gel: ${ }^{18}$}

$\mathrm{pH}$ of formulation

$\mathrm{pH}$ of the each formulation was determined by using $\mathrm{pH}$ meter (Equiptronics, model eq-610). The $\mathrm{pH}$ meter was first calibrated using solutions of $\mathrm{pH} 4.5$ and 7.

\section{Gelation temperature}

Gelation temperature was measured by visual observation method. Two milliliter aliquot of gel was transferred to a test tube, immersed in a water bath. The temperature of water bath was increased slowly at a constant rate of $1^{\circ} \mathrm{C}$ for $2 \mathrm{~min}$ from room temperature to the temperature at which gel formed. The sample was then examined for gelation, which was said to have occurred when the meniscus would no longer move upon tilting the test tube through an angle of $90^{\circ} \mathrm{C}$.

\section{Determination of mucoadhesive strength}

Nasal tissue was isolated after cervical dislocation of the rat. Area $\left(1 \mathrm{~cm}^{2}\right)$ was cut off and attached to the mucoadhesive force determination apparatus. Polymeric solution was applied to the tissue on the lower side. On other side, weights were applied till the tissue isolated from the poly- 
meric material. The weight necessary for the separation was considered and mucoadhesive strength was determined according to the formula (equation 4 and 5) given below:

$$
\text { Mucoadhesive strength }=\frac{\text { Force of adhesion }}{\text { Area }}
$$

Force of adhesion $=\frac{\mathrm{m}(\text { grams }) \times \mathrm{g}(\text { acceleration due to gravity })}{1000}$

Preparation of paliperidone microspheres containing gel ${ }^{19}$ Paliperidone microspheres containing drug equivalent to $10 \mathrm{mg}$ were dispersed in $20 \mathrm{ml}$ water along with the polymers and rest of the procedure was followed to prepare PP microspheres containing gel.

\section{Evaluation of the paliperidone microspheres containing gel Ex vivo drug permeation study ${ }^{20}$}

Fresh nasal mucosa was carefully removed from the nasal cavity of sheep obtained from the local slaughter house. The mucosa was stored in normal saline solution. After the removal of blood and bony cartilage from the mucosal membrane, it was ready for use. Franz diffusion cells (permeation area $4.9 \mathrm{~cm}^{2}$ and capacity $16 \mathrm{~mL}$ ) were placed on six station magnetic stirring unit. Prior to study, nasal mucosa was soaked in diffusion medium (phosphate buffer saline $\mathrm{pH}$ 6.8) for $1 \mathrm{~h}$ and then placed on the receptor cell of the diffusion assembly. Formulation equivalent to $2 \mathrm{mg}$ of drug was placed in donor chamber by uniform application on membrane. Drug permeation study was carried out at $34^{\circ} \mathrm{C}$ for $8 \mathrm{hr}$. Receptor compartment was filled with $16 \mathrm{ml}$ of diffusion medium. Sampling of $1 \mathrm{ml}$ was done at time interval of $0.5,1,2$ up to $8 \mathrm{hr}$, replacing the sampled volume with fresh diffusion medium after each sampling. $1 \mathrm{ml}$ of this sample was further diluted with buffer to $10 \mathrm{ml}$. Absorbance of these diluted solutions was measured spectrophotometerically at $271 \mathrm{~nm}$, and drug permeation was calculated by calibration curve method.

\section{Pharmacodynamic study in mice ${ }^{21}$}

Mice with average weight of $30 \mathrm{~g}$ was selected and deprived of food and water for $24 \mathrm{~h}$ before the experiment. To avoid any effect of the circadian rhythm, the study was performed during 8.00 and $12.00 \mathrm{am}$. The intranasal formulation was administered in mice with the help of micropipette $(5 \mu \mathrm{l} /$ nostril) at the dose of $0.05 \mathrm{mg}$ pali (equivalent to $2 \mathrm{mg} / \mathrm{kg}$ of body weight) followed by intraperitoneal injection of l-dopa $(13 \mathrm{mg} / \mathrm{kg}$ of body weight) and carbidopa ( $3.25 \mathrm{mg} / \mathrm{kg}$ of body weight) after $30 \mathrm{~min}$. The spontaneous motor activity was measured for $1 \mathrm{~min}$ at an interval of $10 \mathrm{~min}, 1 \mathrm{hr}, 2 \mathrm{hr}, 3 \mathrm{hr}$ up to $8 \mathrm{hrs}$ by placing the animals in digital photoactometer.

\section{Nasal mucosal irritation study 22}

Histopathological evaluation of tissue incubated in PBS ( $\mathrm{pH} 7.4$ ) was compared with tissue incubated in the franz diffusion chamber with gel formulation for 8 hours. Tissue was fixed in $10 \%$ buffered formalin $(\mathrm{pH}$ 7.2), routinely processed and embedded in paraffin. Paraffin sections $(7 \mu \mathrm{m})$ were cut on glass slides and stained with hematoxylin and eosin. Sections were examined under a light microscope to detect any damage to the tissue during in vitro permeation by a pathologist blinded to the study.

Stability study

Optimized batch was subjected to stability study. The formulation was stored at $4^{\circ} \mathrm{C}$ to $8^{\circ} \mathrm{C}$ for a period of 3 months. Sampling was done at the end of 8 days, 15 days, 1 month, 2 month and 3 months. The formula- tion was finally evaluated for $\mathrm{pH}$, gelation temperature, assay and in vitro drug release.

\section{RESULT AND DISCUSSION}

\section{Target product profile}

The basic aim of the project was to give extended release of the drug and achieve brain delivery through nasal route. To achieve these aims microspheres were proposed. Microspheres have small particle size and so these should act as small multiple reservoirs to release the drug slowly over a period of time. Nasal route offers challenge in terms of residence time. Anything that enters the nasal cavity tends to be washed away by mucocilliary clearance. Hence the microspheres were incorporated in the mucoadhesive gel structure that should prolong the time for which the microspheres stay in nasal cavity. The gel system was thermo sensitive, giving the advantage of being liquid during handling and forming gel in the nasal cavity.

Hence constraints were put on tangible targets that could have bearing on the overall quality and performance of the product. Microspheres should be spherical; size should be small and have narrow size distribution. Additionally the process should give high percentage yield. Finally they should release the entrapped drug over a required period of time in a predetermined pattern. The prepared microspheres should be homogenously dispersed in the liquid (that will gel when instilled in to nasal cavity) to give uniform dose during administration. The release profile should not significantly deviate after the microspheres have been embodied in gel.

\section{Preparation and evaluation of microspheres}

Initial screening experiments were performed using different polymers and ethyl cellulose was selected for further experiments (results not shown here). Tween 80 being a surfactant played an important role in determining the size of microsphere and percentage yield of the microsphere which in turn controls the drug release. ${ }^{23}$ Different amounts of ethyl cellulose and surfactant were used in a $3^{\wedge} 2$ factorial design to identity a combination that would give a programmed release of 8 hours, small particle size and high percentage yield (Table 1).

Multiple linear regression analysis was performed to equate the multiple factors with each response and mathematical models were generated. Since face centered factorial design was adopted it was possible to simultaneously correlate the independent factors, their quadratic term and the interaction term to the response. As a first step full quadratic models (FM) equating each factor with the responses was generated using Design Expert 8.0.6 trial (StatEase statistical software package). In order to generate the most significant model, the insignificant terms were dropped and only those terms that had $p<0.05$ were retained and these were referred to as reduced models (RM) ${ }^{24}$ Table 2 gives the ANOVA results for $\mathrm{FM}$ and $\mathrm{RM}$ for each factor and following equations were therefore carried forward to interpret the relationship between independent and dependent variables and finally optimization.

(a) Amount of drug released at the end of 30 minutes

$$
\mathrm{Y}_{30}=+13.21-2.55^{\star} \mathrm{X}_{1}+1.62^{*} \mathrm{X}_{2}
$$

The negative sign of coefficient for $\mathrm{X}_{1}$ (amount of polymer) and positive sign of coefficient for $\mathrm{X}_{2}$ (amount of surfactant) indicates that the amount of drug release at the end of $30 \mathrm{~min}$ decreases with increase in amount of polymer and increases as the amount of surfactant increases at all time points. The magnitude of the coefficient for $\mathrm{X}_{1}$ is higher than that for $\mathrm{X}_{2}$ indicating that $\mathrm{X}_{1}$ has more predominant control in deciding the value of response. The model (equation 6) shows linear relationship between the 
Table 1: Coded factors and responses in the factorial design

\begin{tabular}{|c|c|c|c|c|c|c|c|}
\hline Batch Code & $\mathrm{x}_{1}^{*}$ & $\mathrm{X}_{2}{ }^{*}$ & $\begin{array}{c}\% \text { CPR at } \\
30 \mathrm{~min}\end{array}$ & $\begin{array}{c}\% \text { CPR at } \\
240 \mathrm{~min}\end{array}$ & $\begin{array}{l}\% \text { CPR at } \\
480 \mathrm{~min}\end{array}$ & $\%$ yield & Particle size \\
\hline M1 & $-1.00(3.0)$ & $-1.00(0.5)$ & 12.42 & 55.47 & 67.75 & 66.73 & $119.93 \pm 2.23$ \\
\hline M2 & $0.00(4.5)$ & $-1.00(0.5)$ & 11.08 & 49.26 & 62.03 & 67.77 & $126.48 \pm 3.51$ \\
\hline M3 & $1.00(6.0)$ & $-1.00(0.5)$ & 10.47 & 48.13 & 60.86 & 66.85 & $142.80 \pm 4.35$ \\
\hline M4 & $-1.00(3.0)$ & $0.00(1.0)$ & 17.56 & 58.43 & 72.47 & 72.66 & $112.23 \pm 1.56$ \\
\hline M5 & $0.00(4.5)$ & $0.00(1.0)$ & 12.52 & 54.14 & 65.52 & 69.33 & $120.20 \pm 2.13$ \\
\hline M6 & $1.00(6.0)$ & $0.00(1.0)$ & 11.11 & 47.42 & 60.75 & 68.54 & $139.32 \pm 3.12$ \\
\hline M7 & $-1.00(3.0)$ & $1.00(1.5)$ & 17.04 & 55.14 & 70.12 & 72.48 & $108.48 \pm 1.57$ \\
\hline M8 & $0.00(4.5)$ & $1.00(1.5)$ & 16.52 & 51.26 & 61.12 & 69.56 & $112.23 \pm 2.45$ \\
\hline M9 & $1.00(6.0)$ & $1.00(1.5)$ & 10.15 & 51.33 & 62.41 & 65.40 & $132.57 \pm 3.41$ \\
\hline
\end{tabular}

$\mathrm{X}_{1}=$ Amount of ethyl cellulose.

$\mathrm{X}_{2}=$ Amount of Tween 80.

* Values in parenthesis indicate the actual amount of $\mathrm{X}_{1}$ and $\mathrm{X}_{2}$ in $\mathrm{g}$ and $\mathrm{ml}$ respectively.

CPR values are the average of dissolution studies for 6 tablets.

$\%$ yield indicates average of 3 experiments.

Table 2: Summary of ANOVA table for dependent variables from factorial design

\begin{tabular}{cccccccc}
\hline & & $\begin{array}{c}\text { Sum of } \\
\text { Squares }\end{array}$ & df & Mean Square & F Value & $\begin{array}{c}\text { p-value } \\
\text { Prob }>\text { F }\end{array}$ & R-Squared \\
\hline Y30 & FM & 62.23 & 5 & 12.45 & 4.04 & 0.1399 & 0.8707 \\
& RM & 54.78 & 2 & 27.39 & 9.85 & 0.0127 & 0.7665 \\
Y240 & FM & 96.23 & 5 & 19.25 & 3.77 & 0.1519 & 0.8627 \\
& RM & 85.80 & 2 & 42.90 & 10.00 & 0.0123 & 0.7692 \\
Y480 & FM & 142.89 & 5 & 28.58 & 6.97 & 0.0705 & 0.9207 \\
& RM & 116.97 & 2 & 58.48 & 9.18 & 0.0150 & 0.7536 \\
\%yield & FM & 47.99 & 5 & 9.60 & 13.82 & 0.0278 & 0.9584 \\
& RM & 39.60 & 3 & 13.20 & 6.30 & 0.0376 & 0.7909 \\
& FM & 1207.66 & 5 & 241.53 & 83.50 & 0.0020 & 0.9929 \\
& $* *$ & 1207.66 & 5 & 241.53 & 83.50 & 0.0020 & 0.9929 \\
\hline
\end{tabular}

** FM retained.

Table 3: Coded quantities of the best batch and their desirability

\begin{tabular}{|c|c|c|c|c|c|c|c|}
\hline & & & Lower & Upper & Lower & Upper & \\
\hline Name & & Goal & Limit & Limit & Weight & Weight & Importance \\
\hline $\mathrm{X}_{1}$ & & is in range & -1 & 1 & 1 & 1 & 3 \\
\hline $\mathrm{X}_{2}$ & & is in range & -1 & 1 & 1 & 1 & 3 \\
\hline Y30 & & maximize & 10.15 & 17.56 & 1 & 1 & 3 \\
\hline Y240 & & maximize & 47.42 & 58.43 & 1 & 1 & 3 \\
\hline Y480 & & maximize & 60.75 & 72.47 & 1 & 1 & 3 \\
\hline \%yield & & maximize & 65.4 & 72.66 & 1 & 1 & 3 \\
\hline Particle size & & minimize & 108.48 & 142.8 & 1 & 1 & 3 \\
\hline \multicolumn{8}{|c|}{ Solution having a desirability of 0.912} \\
\hline $\mathrm{X}_{1}$ & $\mathrm{X}_{2}$ & Y30 & Y 240 & Y480 & \%Yield & & Particle size \\
\hline-1.00 & 1.00 & 17.3794 & 56.7917 & 69.6694 & 73.475 & & 107.197 \\
\hline
\end{tabular}


Table 4: Pharmacodynamic activity (spontaneous motor activity) in normal mice

\begin{tabular}{|c|c|c|c|c|c|c|c|c|c|}
\hline \multirow[t]{2}{*}{ Treatment group $(n=6)$} & \multicolumn{9}{|c|}{ Time in min } \\
\hline & 10 & 60 & 120 & 180 & 240 & 300 & 360 & 420 & 480 \\
\hline Control group(water) & 53 & 55 & 52 & 55 & 58 & 54 & 55 & 52 & 54 \\
\hline Palipeidone oral solution (from tablet) & 48 & 44 & 38 & 38 & 41 & 43 & 42 & 48 & 52 \\
\hline Paliperidone nasal in situ gel (IN) & 49 & 46 & 42 & 35 & 33 & 33 & 31 & 33 & 34 \\
\hline Paliperidone drug solution (IN) & 43 & 40 & 34 & 41 & 43 & 42 & 45 & 52 & 50 \\
\hline $\begin{array}{l}\text { Positive control (haloperidone solution } \\
\text { IN) }\end{array}$ & 46 & 42 & 40 & 34 & 30 & 38 & 39 & 43 & 48 \\
\hline
\end{tabular}

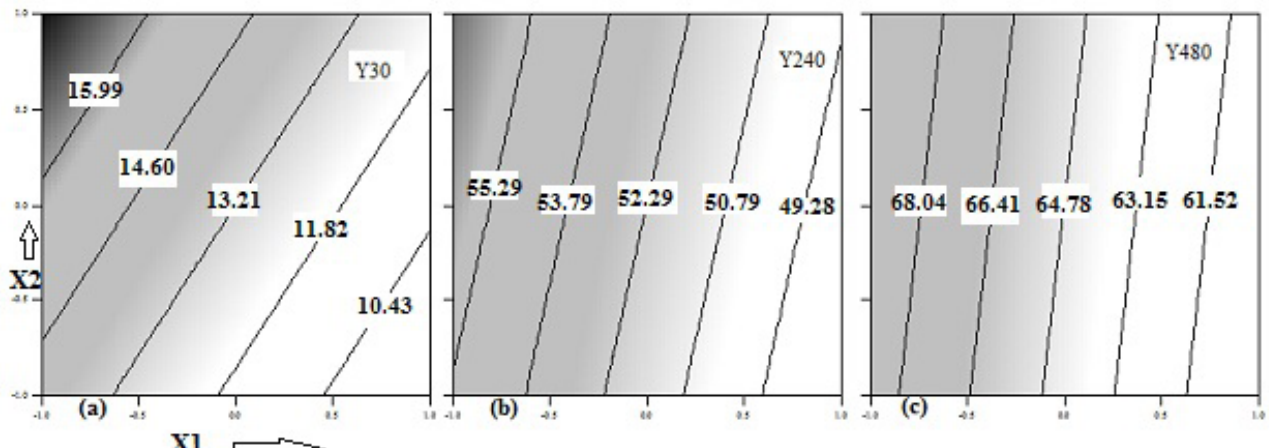

$\mathrm{Xl}$

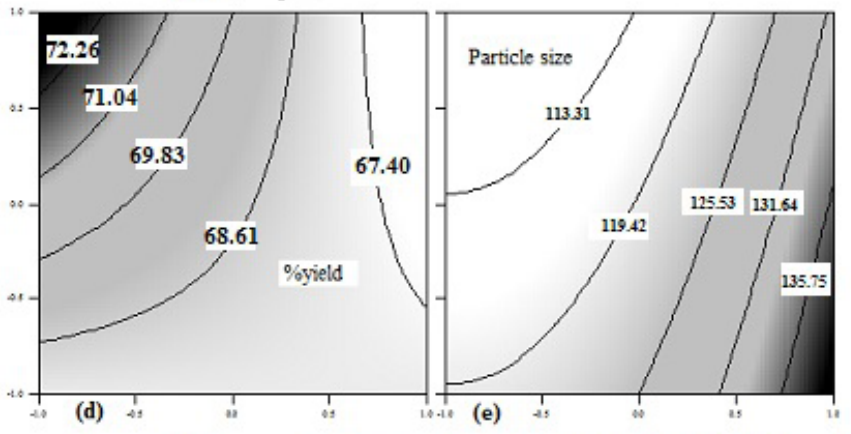

Figure 1: Contour plots for $\mathrm{Y} 30, \mathrm{Y} 240, \mathrm{Y} 480, \%$ yield and particle size.

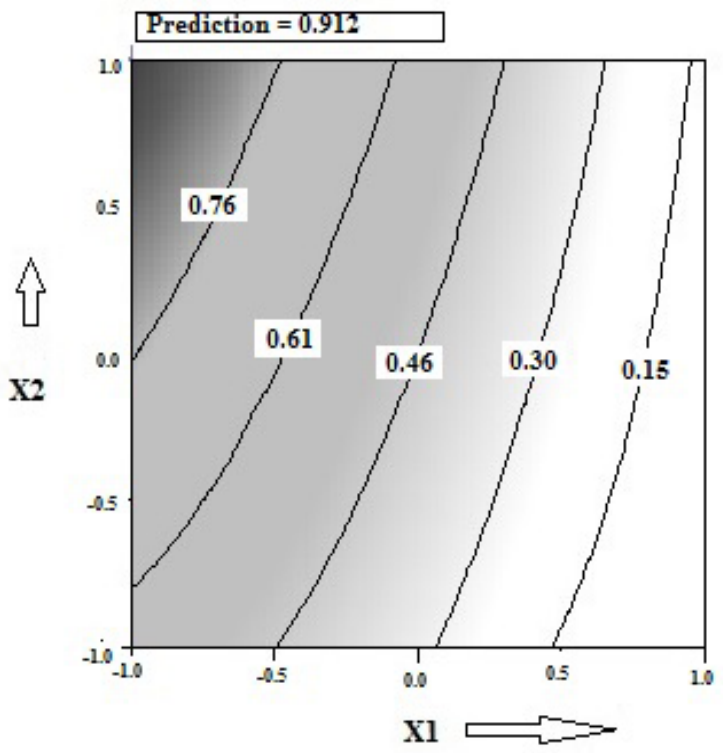

Figure 2: Desirability plot. 

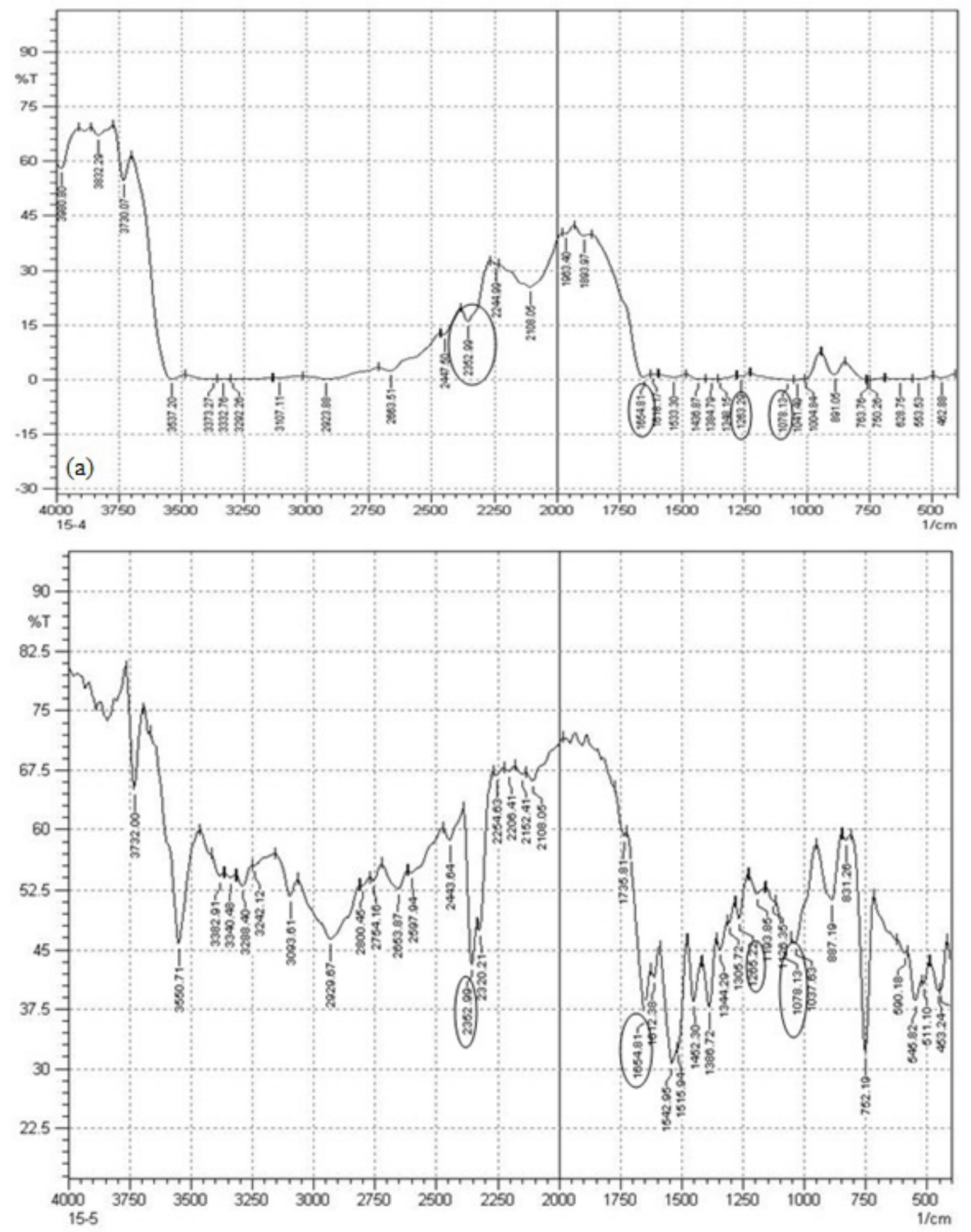

Figure 3 (a): FTIR spectra of Paliperidone Palmitate (b): FTIR spectra of Drug Polymer mixture. 

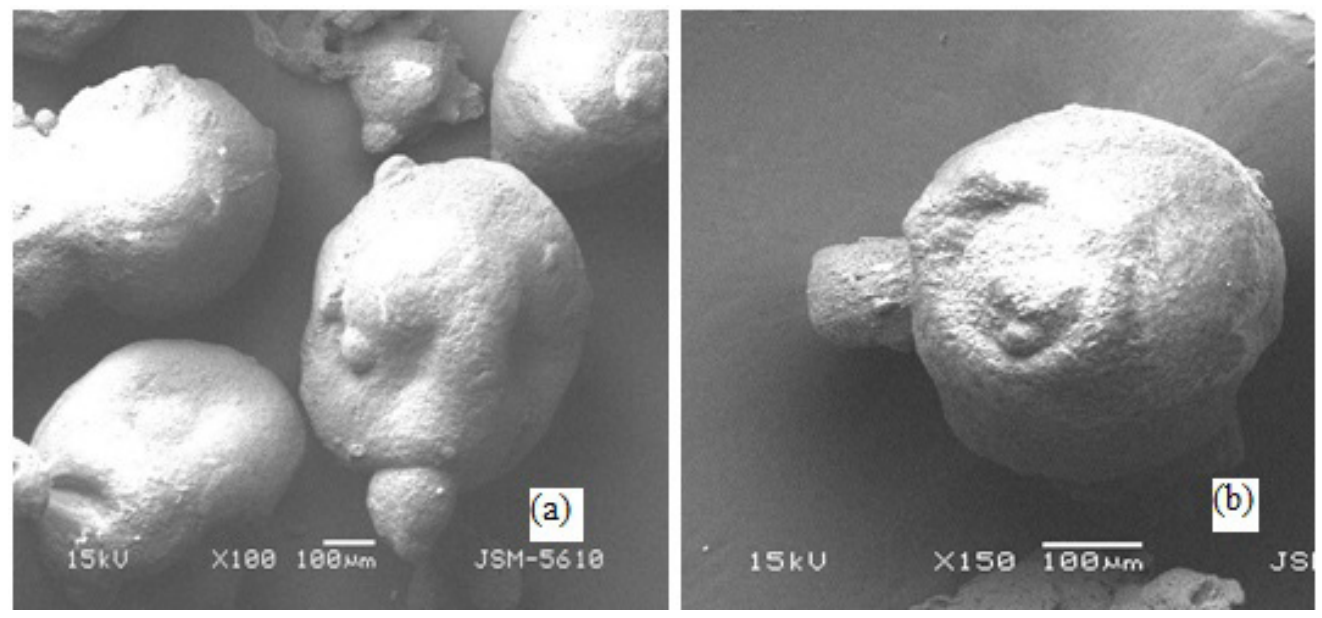

Figure 4: Scanning electron micrographs of microspheres of Batch A3.
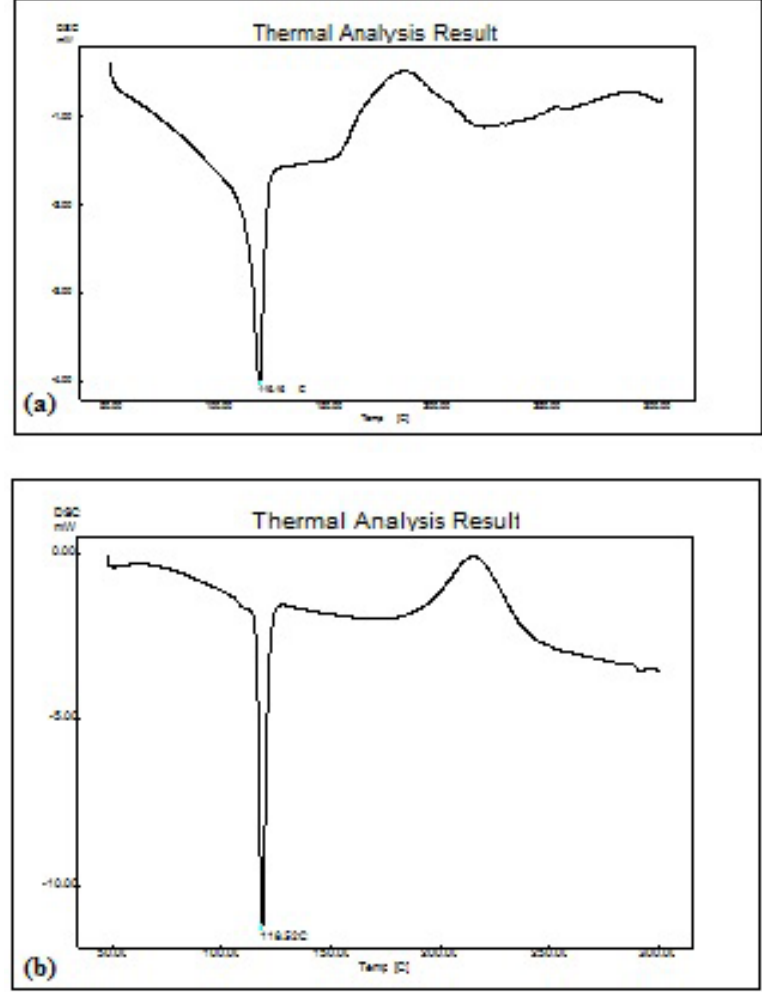

Figure 5: DSC of (a) plain drug and (b) microspheres.

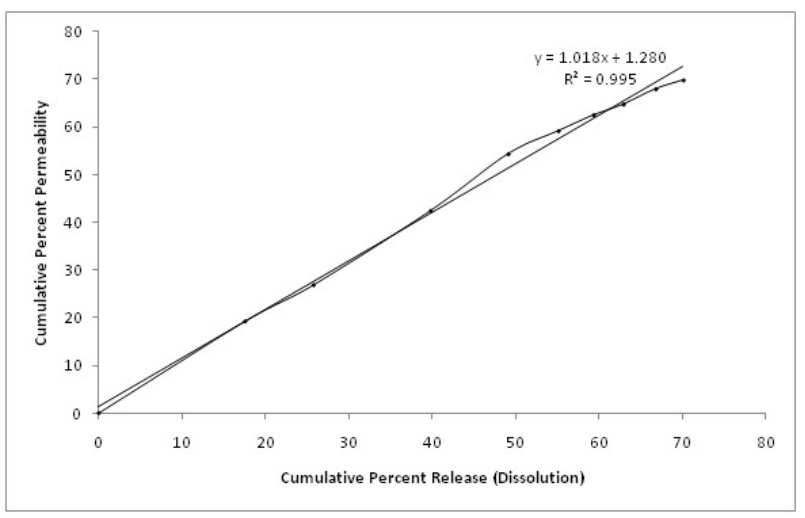

Figure 6: Correlation between percent drug release and percent permeability.

Figure 7: Histopathological slides a) Normal (Control) b) IPA treated - Infiltration of leukocytes, hypertrophy of cells c) Microemulsion treated - Intact goblet cells. 
response and the factors. The linearity of the equation is substantiated by the straight lines in the contour plot (Figure 1a).

(b) Amount of drug released at the end of $240 \mathrm{~min}$

$$
\mathrm{Y}_{240}=+52.28667-3.69333 * \mathrm{X}_{1}+0.81167 * \mathrm{X}_{2}
$$

(c) Amount of drug released at the end of $480 \mathrm{~min}$

$$
\mathrm{Y}_{480}=+64.78111-4.38667 * \mathrm{X}_{1}+0.50167 * \mathrm{X}_{2}
$$

Significance of the amount of polymer increases as the time progresses as indicated by higher values of coefficient for $\mathrm{X}_{1}$ (polymer amount) as compared to $\mathrm{X}_{2}$ (Tween 80) at 240 and 480 mins (equation 7 and 8). This may be because that initial drug release may be affected by the amount of drug on surface of microspheres but with time the diffusional path length decides the amount of drug release which in turn will depend on the polymer amount. Nevertheless there is absence of interaction of the independent factors on percentage release at the end of $240 \mathrm{~min}$ and 480 min as exemplified by straight lines in Figure $1 \mathrm{~b}$ and $1 \mathrm{c}$.

(d) $\%$ yield

$\%$ Yield $=+68.81333-1.84667 * \mathrm{X}_{1}+1.01500 * \mathrm{X}_{2}-1.80000 * \mathrm{X}_{1}^{*} \mathrm{X}_{2}$

(e)Particle size

$$
\begin{aligned}
\text { Particle size }= & +119.75+12.34{ }^{\star} \mathrm{X}_{1}-5.99{ }^{*} \mathrm{X}_{2}+ \\
& 0.30 * \mathrm{X}_{1}{ }^{\star} \mathrm{X}_{2}+6.25 * \mathrm{X}_{1}^{2}-0.17 \mathrm{X}_{2}^{2}
\end{aligned}
$$

Percentage yield and particle size show more complicated relationship with the two factors (equation 9 and 10). The importance of interaction and quadratic terms comes in to play for percentage yield and particle size. This is emphasized by the curvy nature of the lines on the graph (Figure 1d and e). Entrapment efficiency of the experimental design batches varied between 68.24 to $73.28 .^{25}$

The generation of mathematical models using systematic design of experiments helps in optimizing the formulations. It is expected that the microspheres release around $20 \%$ drug in the first $30 \mathrm{~min}$ to achieve immediate onset of action. The product was expected to retain for 8 hours and so additional contraints were put on the release at the end of 4 hours and 8 hours. Since the drug has half-life of around 24 hours (http://yoda. yale.edu/sites/default/files/nct00074477.pdf - accessed on 23/11/2015) the effect should not diminish easily. Additionally it was expected that the particle size should be small so that during administration it should form a uniform dispersion ascertaining correct dose. Percentage yield on higher side would make the process economical. Constraints were therefore put on the response values to identify the optimum combination of factors. Since the range of values obtained for responses was such that maximum value of release at different time points, minimum particle size possible and maximum yield were considered desirable (Table 3 ). ${ }^{26}$

Batch 7, when $\mathrm{X}_{1}$ was lowest and $\mathrm{X}_{2}$ was highest, showed highest desirability of 0.912 (Figure 2) and hence microspheres of this batch were studied for FTIR, SEM and DSC. Figure 3a shows the characteristic peaks of the drug i.e. 2984, 2804, 2761, 1654, 1608, 1537, 1267 and $1121 \mathrm{~cm}-1$ which are retained in FTIR spectra of the drug - polymer mixture indicating no drug - polymer interaction (Figure 3b). Figure $4 \mathrm{a}$ and Figure $4 \mathrm{~b}$ show scanning electron micrographs of microspheres at a magnification of $100 \mathrm{X}$ and $150 \mathrm{X}$ respectively. The surface of the microspheres is slightly roung but the edges are smoothly rounded giving a free flowing product. The DSC of the drug alone and drug loaded microspheres are similar (endothermic peak close to $116^{\circ} \mathrm{C}$ ). This could be because of certain amount of drug on the surface of the microspheres. The intensity of the peak in drug loaded microspheres reduces a bit. Apart from that no widening of the peak is observed confirming the crystalline structure of the drug (Figure 5).

\section{Kinetics of drug release}

The kinetics of drug release was determined using percentage drug release with respect to time. The data was fitted in zero order, first order and Higuchi model. Lowest $\mathrm{F}$ value and highest value for $\mathrm{R}^{2}$ was obtained for Higuchi's model, indicating that the mechanism of drug release was diffusion. ${ }^{27}$

\section{Preparation and evaluation of thermoreversible gel}

Temperature of nasal cavity is close to $34^{\circ} \mathrm{C}$ and so combination of PF-127 and HPMC that would exhibit thermo-reversible property at a temperature less than $34^{\circ} \mathrm{C}$ was identified. Gel prepared using $1 \% \mathrm{HPMC}$ exhibited a gelling temperature of $32^{\circ} \mathrm{C}, \mathrm{pH}$ of 5.2 and mucoadhesive strength of 1176 dynes $/ \mathrm{cm}^{2}$.

\section{Characeterization of PP loaded microspheres containing gel Ex Vivo permeation study}

The permeation study through sheep nasal mucosa showed a release pattern which was similar to the In vitro drug release indicating that the entrapment in gel did not significantly affect the permeation through the mucosa (Figure 6). A high value of correlation coefficient (0.995) substantiates the fact. ${ }^{28}$ During the preparation of microspheres some amount of drug always remains on the surface of the microspheres. The authors hypothesize that this drug gets in equilibrium with the gel so when this gel is spread as a thin film for the ex vivo studies it becomes immediately available for permeation. Machado et al have reported similar findings for PLGA microspheres of wound healing agent in a pluronic gel. Susan has tried to explain similar behavior based on the amount of drug below the saturation solubility and above the saturation solubility. ${ }^{29,30}$

The drug transport mechanism of the same formulations was determined by using the Korsmeyer-Peppas exponential equation. Form the plot of $\log (\mathrm{Mt} / \mathrm{M})$; fraction of drug released at time " $\mathrm{t}$ " versus log of time. The diffusion exponent ' $n$ ' was calculated from equation and was found to be 0.478 indicating fickian diffusion.

\section{Pharmacodynamic study in mice}

Table 4 gives the number of counts at different time points for different treatments. All the treatments show decrease in count as compared to control group (water) indicating the efficacy of all the treatments. The oral and intranasal administration gives faster onset of action as compared to gel formulation which is very much expected as drug takes some time to diffuse from microspheres and then the gel matrix structure but once the counts reduce the effect lingers on for more duration from gel than any other treatment (Table 4).

\section{Nasal mucosal irritation study}

Figure 7 shows the tissue toxicities of different treatments. Figure 7 a shows the normal tissue, Figure $7 \mathrm{~b}$ show the damage caused by isopropyl alcohol (IPA) treatment which was used as positive control. The IPA treatment causes the infiltration of leucocytes in to the cells and hypertrophy of the cells. The gel formulation does not cause any visible damage to the cells as evidenced by the intact goblet cells (Figure 7c).

\section{Stability Study}

The gelation temperature and $\mathrm{pH}$ of the gel formulation did not change significantly at different sampling time points $(p>0.05)$; the assay value and dissolution profile also remained unaltered at the end of stability period $(f 2>50)$ indicating the stability of the formulated product.

\section{CONCLUSION}

Theromoreversible gel containing paliperidone palmitate for nose to brain delivery was developed. The developed formulation is expected to 
be quick in action and give effect for a prolonged duration as compared to conventional dosage forms.

\section{ACKNOWLEDGEMENT}

The authors wish to acknowledge the help of Dr. Mehul Chorawala and Mr. Dharmik Mehta in performing animal experiments.

\section{CONFLICT OF INTEREST}

The authors declare no conflict of interest.

\section{ABBREVIATIONS USED}

PP: Paliperidone Palmitate; FTIR: Fourier transform infrared; DSC: Differential Scanning Calorimetry; SEM: Scanning electron microscopy; PF-127: Pluronic F-127; $\mathbf{X}_{1}$ : Amount of ethyl cellulose; $\mathbf{X}_{2}$ : Amount of Tween 80; Y30, Y240 and Y480: Percentage drug release at the end of 30,240 and 480 minutes respectively; FM: Full model; RM: Reduced model; IN: Intranasal.

\section{ABOUT AUTHORS}

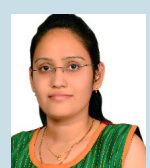

Apurva Maniar: Has completed her B. Pharm. and M. Pharm from K. B. Institute of Pharmaceutical Education and Research. Presently she is working with State Bank of India.

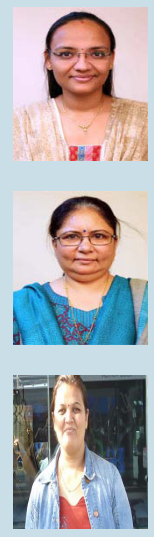

Grishma Patel: Is a doctoral student at the Kadi Sarva Vishwavidyalaya (Gujarat, India), completed B. Pharm and M. Pharm from Ganpat University (Gujarat, India), Her doctoral research focused on the development of lipid based drug delivery systems for poorly soluble drug. She is working on various key area including fast dissolving system, oral solids, colon targeted drug delivery with probiotic, sustained release drug delivery, liposomal drug delivery, nano particulate drug delivery like microsphere etc. She is well acquainted with use of statistics software such as Design-Expert $\circledast$, Minitab® software, Graph Pad Prism software, MS Excel, etc.

Pragna K Shelat: Obtained her Ph. D. degree in 2006 from School of Science, Gujarat University, Ahmedabad. She has worked with industries like Cadila Healthcare Ltd., and Core Parenterals Ltd. (Gujarat, India). Currently, she is positioned as Head of Department and professor at the Pharmaceutics Department of K. B. Institute of Pharmaceutical Education and Research (Gujarat, India). Dr. Shelat is working on various key areas including patient centric drug delivery system, development of modified oral delivery system. She is a member of board of studies in different Universities. She also involved in Industrial projects, granting projects.

Dr. Anita Lalwani Is working as professor in the department of pharmaceutics at K. B. Institute of Pharmaceutical Education and Research, Gandhinagar, Gujarat. She has 18 years of academic and 8 years of research experience. Professor Lalwani has been actively working on oral drug delivery systems, targeting different segments of gastrointestinal tract for enhancing the therapeutic effectiveness of drug molecule. She has applied systematic design approach in her research work and firmly substantiates her results with statistical treatment. She is well conversant with softwares like Design Expert, Minitab, Graph Pad prism and SPSS.

\section{REFERENCES}

1. Kramer M. et al. Paliperidone palmitate, a potential long-acting treatment for patients with schizophrenia. Results of a randomized, double-blind, placebocontrolled efficacy and safety study. Int J Neuropsychopharmacol. 2010;13(5): 635-47.

2. Vermeulen AMC. and Wouters AJ. Dosing regimen associated with long acting injectable paliperidone esters. 2009. Google Patents.

3. Keith SJ. et al. Academic highlights: guidelines for the use of long-acting injectable atypical antipsychotics. J Clin Psychiatry. 2004;65(1):120-31.

4. Kramer M. et al. Paliperidone extended-release tablets for prevention of symptom recurrence in patients with schizophrenia: a randomized, double-blind, placebocontrolled study. J Clin Psychopharmacol. 2007;27(1):6-14.

5. Kumar A, Pandey AN, Jain SK. Nasal-nanotechnology: revolution for efficient therapeutics delivery. Drug Deliv. 2015:1-13.

6. Pires A. et al. Intranasal drug delivery: how, why and what for? J Pharm Pharm Sci. 2009;12(3):288-311.

7. Illum L. Is nose-to-brain transport of drugs in man a reality? J Pharm Pharmacol. 2004; 56(1):3-17.

8. Duchateau GS, Zuidema J, Merkus FW. Bioavailability of propranolol after oral, sublingual, and intranasal administration. Pharm Res. 1986;3(2):108-11.

9. Costantino HR. et al. Intranasal delivery: Physicochemical and therapeutic aspects. International Journal of Pharmaceutics. 2007;337(1-2):1-24.

10. Leng, D. et al. Development and comparison of intramuscularly long-acting paliperidone palmitate nanosuspensions with different particle size. Int J Pharm. 2014;472(1-2):380-5

11. Vyas TK. et al, Preliminary brain-targeting studies on intranasal mucoadhesive microemulsions of sumatriptan. AAPS Pharm SciTech. 2006;7(1):p.E8.

12. Jain, SA. et al, Formulation and evaluation of nasal mucoadhesive microspheres of sumatriptan succinate. J Microencapsul. 2009;26(8):711-21.
13. Vyas, TK. et al. Intranasal mucoadhesive microemulsions of clonazepam: preliminary studies on brain targeting. J Pharm Sci. 2006;95(3):570-80

14. Jogani W. et al. Intranasal mucoadhesive microemulsion of tacrine to improve brain targeting. Alzheimer Dis Assoc Disord. 2008;22(2):116-24.

15. de Francisco LM, Cerquetani JA Bruschi ML. Development and characterization of gelatin and ethylcellulose microparticles designed as platforms to delivery fluoride. Drug Dev Ind Pharm. 2013;39(11):1644-50.

16. Abbas Z, Marihal S. Gellan gum-based mucoadhesive microspheres of almotriptan for nasal administration: Formulation optimization using factorial design characterization, and in vitro evaluation. J Pharm Bioallied Sci. 2014;6(4):267-77.

17. Kumar A. et al. Optimization of combinational intranasal drug delivery system for the management of migraine by using statistical design. Eur J Pharm Sci, $2015 ; 70: 140-51$

18. Bhandwalkar MJ, Avachat AM. Thermoreversible nasal in situ gel of venlafaxine hydrochloride: formulation, characterization, and pharmacodynamic evaluation. AAPS Pharm Sci Tech. 2013;14(1):101-10.

19. Sharma S, Lohan S, Murthy RS. Formulation and characterization of intranasal mucoadhesive nanoparticulates and thermo-reversible gel of levodopa for brain delivery. Drug Dev Ind Pharm. 2014;40(7):869-78.

20. Chandrakantsing V. et al. Novel surface modified solid lipid nanoparticles as intranasal carriers for ropinirole hydrochloride: application of factorial design approach. Drur Deliv. 2013;20(1):47-56.

21. B. Patel R. et al. Risperidone Microemulsion for Transnasal Delivery: Pharmacodynamic and Pharmacokinetic Evaluation. Pharmaceutical Nanotechnology. 2013:1(1):44-53

22. Bhanushali RS. et al. Nanoemulsion based Intranasal Delivery of Antimigraine Drugs for Nose to Brain Targeting. Indian Journal of Pharmaceutical Sciences. $2009 ; 71(6): 707-9$ 
23. Aydogan E. et al. Process and formulation variables of pregabalin microspheres prepared by w/o/o double emulsion solvent diffusion method and their clinical application by animal modeling studies. Drug Dev Ind Pharm. 2015;41(8):1311-20

24. Lalani J. et al. Protein-Functionalized PLGA Nanoparticles of Lamotrigine for Neuropathic Pain Management. AAPS Pharm Sci Tech. 2015;16(2):413-427.

25. Jain A. and Jain SK. Formulation and optimization of temozolomide nanoparticles by 3 factor 2 level factorial design. Biomatter. 2013;3(2):e25102.

26. Zhang W. et al. Development of a vaginal delivery film containing EFdA, a novel anti-HIV nucleoside reverse transcriptase inhibitor. International Journal of Pharmaceutics, 2014;461:203-13.
27. Thakare M. et al. Formulation parameters and release mechanism of theophylline loaded ethyl cellulose microspheres: effect of different dual surfactant ratios. Pharm Dev Technol. 2013;18(5):1213-9.

28. Parejiya PB. et al. In vivo performance evaluation and establishment of IVIVC for osmotic pump based extended release formulation of milnacipran $\mathrm{HCl}$. Biopharmaceutics \& Drug Disposition, 2013;34(4):227-35.

29. Machado HA. et al. Release of a wound-healing agent from PLGA microspheres in a thermosensitive gel. Biomed Res Int. 2013 Article ID 387863 (11 pages).

30. Hua S. Comparison of in vitro dialysis release methods of loperamide-encapsulated liposomal gel for topical drug delivery. International Journal of Nanomedicine. 2014;30(9):735-44. 